Supporting Information

\title{
Infrared invisibility cloak based on polyurethane- tin oxide composite microtubes
}

Jihun Ahn, ${ }^{\dagger,}$ Taekyung Lim, ${ }^{\ddagger}{ }^{\circledR}$ Chang Su Yeo, ${ }^{\dagger}$ Taekuk Hong, ${ }^{\ddagger}$ Sang-Mi Jeong, ${ }^{\ddagger}$ Sang Yoon Park, ${ }^{* \dagger}$ and Sanghyun $\mathrm{Ju}^{*},{ }^{*}$

${ }^{\dagger}$ Advanced Institutes of Convergence Technology, Seoul National University, Suwon-si, Gyeonggi-do 16229, Republic of Korea

tDepartment of Physics, Kyonggi University, Suwon, Gyeonggi-Do 16227, Republic of Korea

*E-mail: yoonpark77@ snu.ac.kr (S. Y. Park).

*E-mail: shju@kgu.ac.kr (S. Ju). 


\section{S1. Images of the polyurethane (PU) microtube}
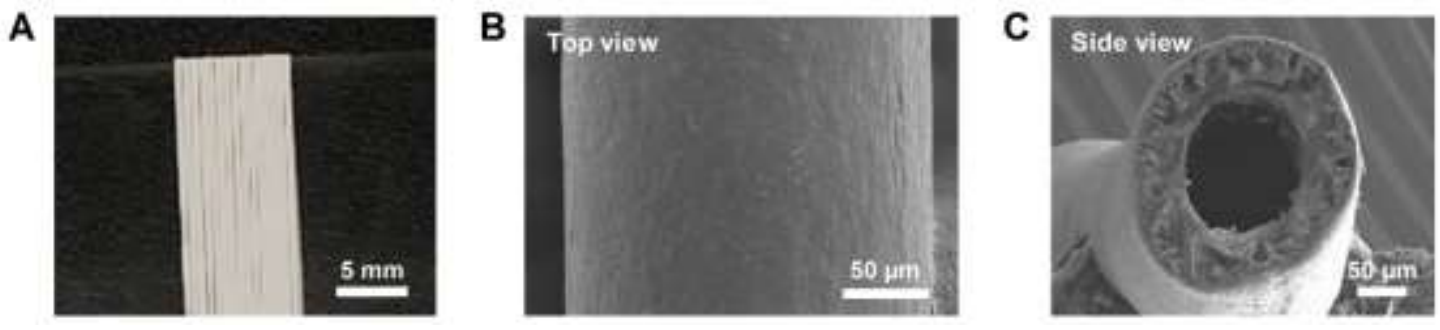

Figure S1. Optical and electron microscopy images of a pure PU microtube. (A) Optical image of PU microtubes densely wound around a glass plate. (B) Field-emission scanning electron microscopy (FE-SEM) image of a single strand of the PU microtube. (C) Cross-sectional SEM image of the PU microtube obtained for observing the internal structure.

Figure S1 shows the FE-SEM image of a pure PU microtube. As shown, the produced PU microtube has a smooth surface with a diameter of $\sim 200 \mu \mathrm{m}$. The cross-sectional view shows the presence of a $\sim 110-\mu \mathrm{m}$-diameter hole within the pure PU microtube. 
S2. Chemical composition of the $\mathrm{PU}-\mathrm{SnO}_{2}$ composite microtube before and after treating with (1H,1H,2H,2H-heptadecafluorodec-1-yl)phosphonic acid (HDF-PA)
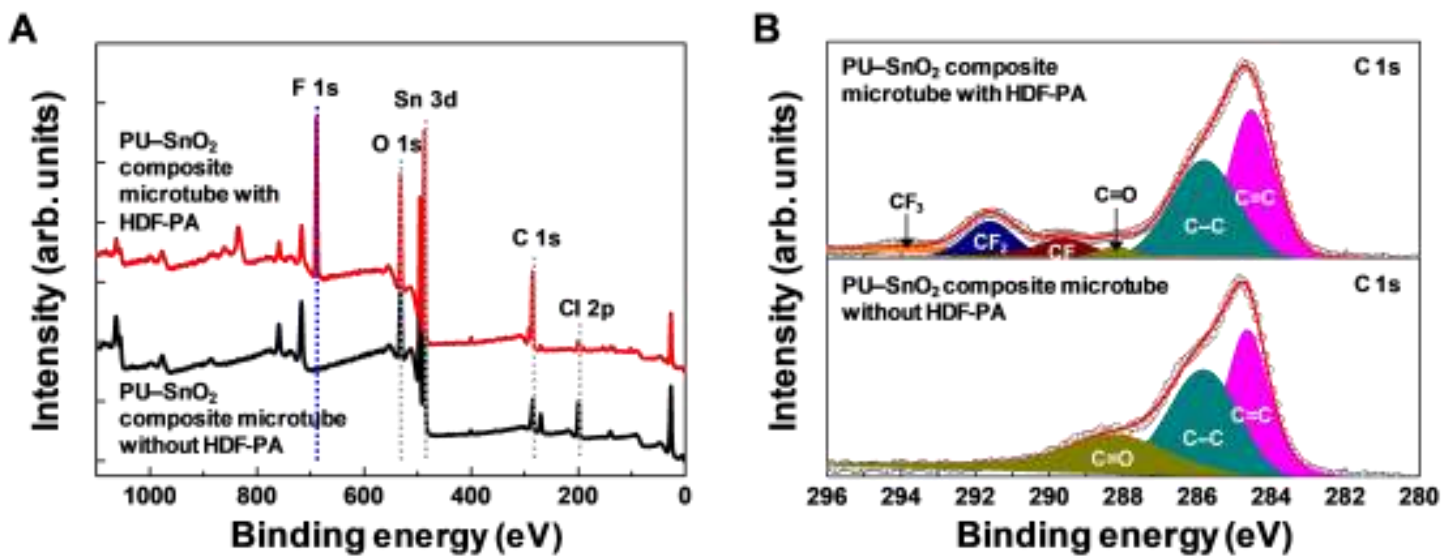

Figure S2. (A) The survey X-ray photoelectron spectra (XPS) and (B) the C 1s spectrum of PU$\mathrm{SnO}_{2}$ composite microtubes before and after HDF-PA treatment.

Figure 2 shows the XPS spectra of $\mathrm{PU}-\mathrm{SnO}_{2}$ composite microtube which was chemically bonded with a self-assembled monolayer of HDF-PA to impart hydrophobicity. Figure S2(A) shows that the fluorocarbon chains are attached to the microtube through the self-assembly of HDF-PA with $\mathrm{SnO}_{2}$ in the $\mathrm{PU}-\mathrm{SnO}_{2}$ composite microtubes. Thus, a peak for fluorine at $\sim 690 \mathrm{eV}$ was discovered only in the PU-SnO 2 composite microtube treated with HDF-PA. Figure S2(B) shows the C 1s spectrum of the PU-SnO 2 composite microtube before and after treating with HDF-PA. Both samples show $\mathrm{C}$ 1s peaks that mainly originate from the $\mathrm{C}=\mathrm{C}(284.6 \mathrm{eV}), \mathrm{C}-\mathrm{C}(285.8 \mathrm{eV})$, and $\mathrm{C}=\mathrm{O}(288.2 \mathrm{eV})$ bonds owing to $\mathrm{SnO}_{2}$ and $\mathrm{PU}$ comprising the microtube. In contrast, the fluorine peaks corresponding to $\mathrm{CF}(289.6 \mathrm{eV}), \mathrm{CF}_{2}(291.6 \mathrm{eV})$, and $\mathrm{CF}_{3}(293.5 \mathrm{eV})$ are additionally detected only in the PU-SnO 2 composite microtube treated with HDF-PA. 


\section{S3. Atomic force microscopy (AFM) images of the $\mathrm{PU}-\mathrm{SnO}_{2}$ composite microtubes}
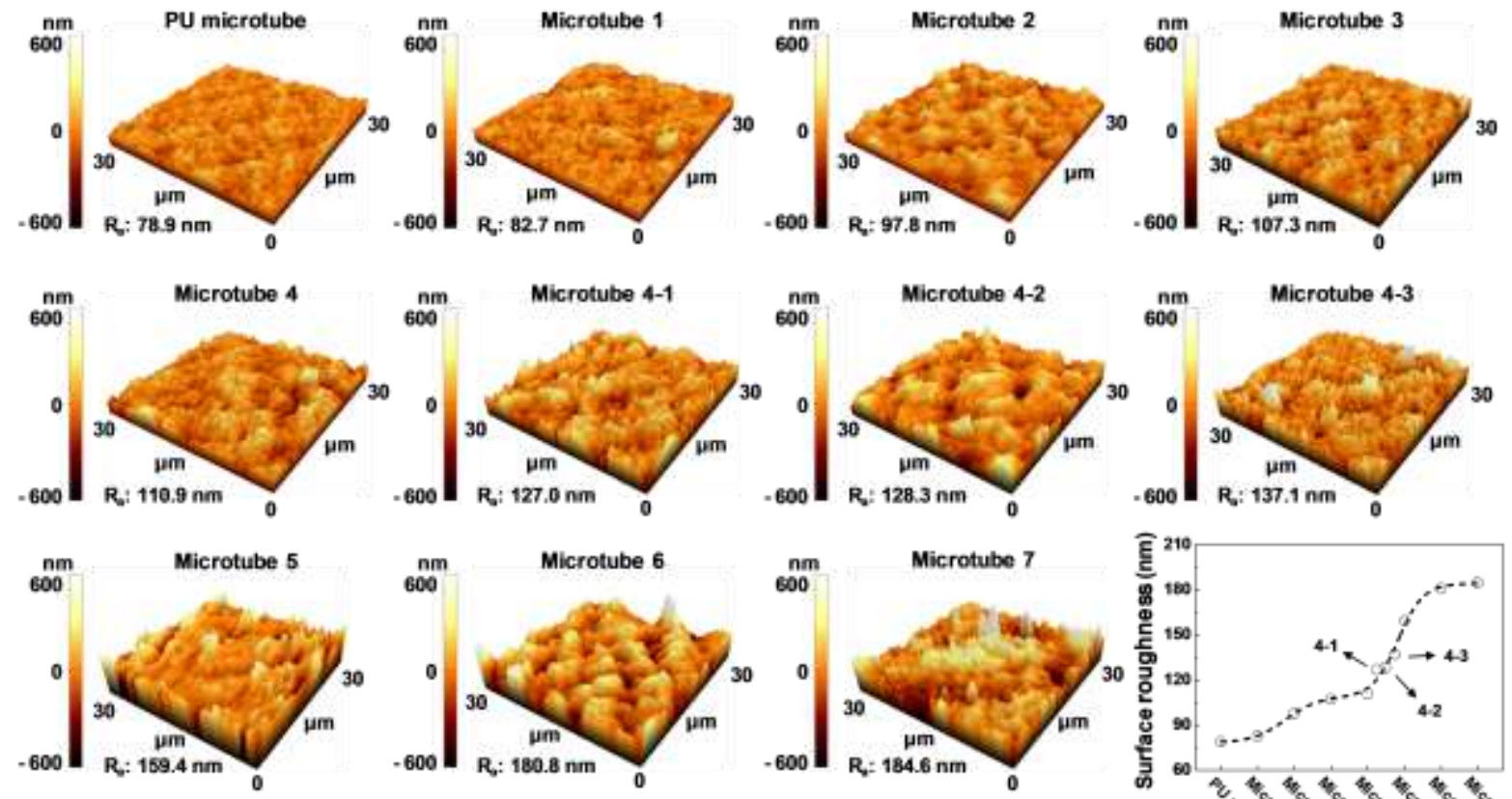

Figure S3. AFM images of various $\mathrm{PU}-\mathrm{SnO}_{2}$ composite microtubes.

AFM analysis was performed to verify the surface roughness of the eleven types of $\mathrm{PU}-\mathrm{SnO}_{2}$ composite microtubes prepared with different $\mathrm{PU}: \mathrm{SnO}_{2}$ ratios. Figure $\mathrm{S} 3$ shows the AFM topographic images of the surface of each microtube. The root mean roughness (RMS) values increased gradually from 78.9 for PU microtube to $82.7,97.8,107.3,110.9,159.4,180.8$, and 184.6 nm for Microtube 1, Microtube 2, Microtube 3, Microtube 4, Microtube 5, Microtube 6, and Microtube 7, respectively. In particular, the roughness increased relatively sharply between Microtube 4 and Microtube 5. AFM analysis with additionally produced composite microtubes showed mean heights of 127.0, 128.3, and 137.1 nm (Microtube 4-1, Microtube 4-2, and Microtube 4-3, respectively). 

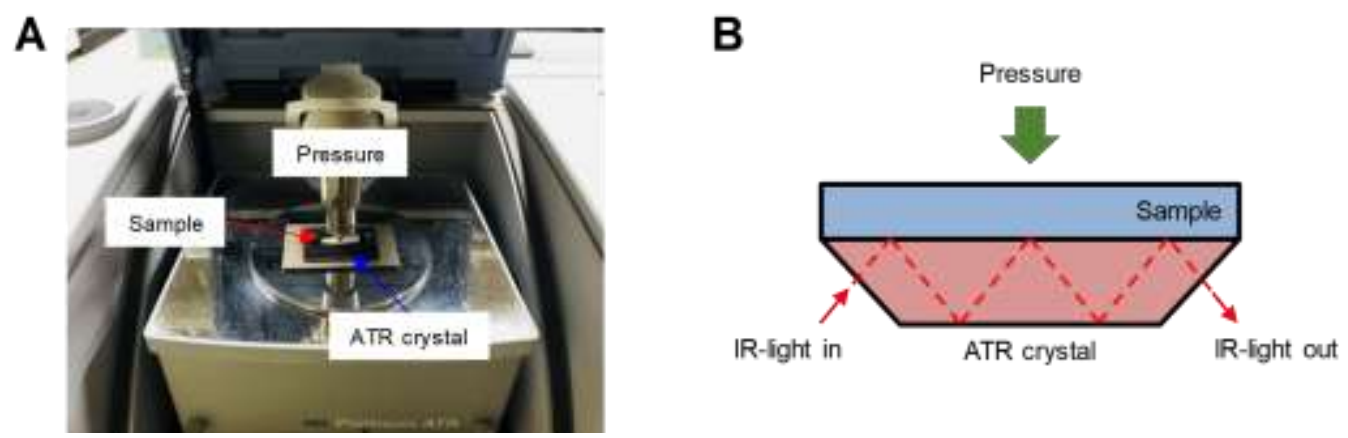

Figure S4. (A) Setup image of the ATR measurement of the $\mathrm{PU}-\mathrm{SnO}_{2}$ microtube textile. (B) Schematic image of the ATR-mode FTIR system.

Figure S4 shows the setup and schematic images of the ATR-mode FT-IR. The PU-SnO 2 microtube textile is located on the ATR crystal, the IR source is incident on the side of the ATR crystal, and the IR reflection on the $\mathrm{PU}-\mathrm{SnO}_{2}$ microtube textile is repeated to recognize the value entering the IR detector. 


\section{S5. The IR- and thermal radiation-shielding properties}

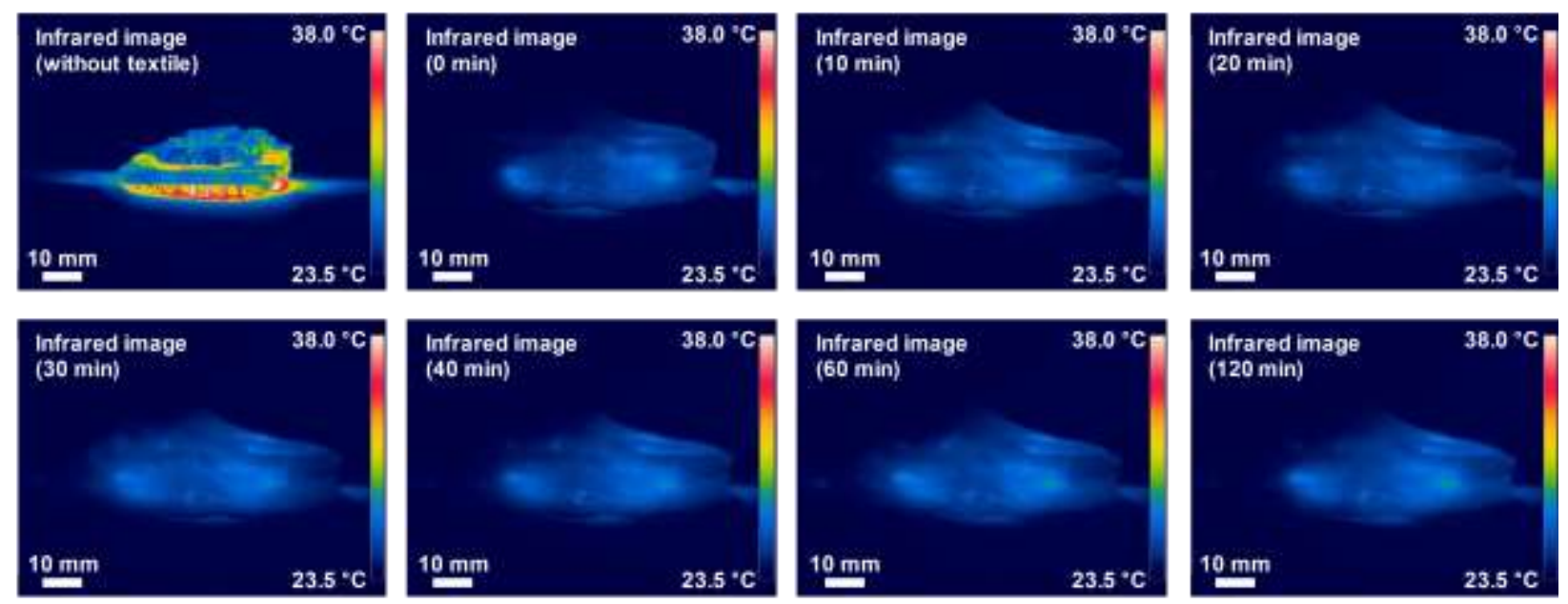

Figure S5. IR- and thermal radiation-shielding properties of a textile produced with $\mathrm{PU}-\mathrm{SnO}_{2}$ composite microtubes (Microtube 5) over time.

Figure S5 shows the infrared camera image of the tank over time. The initial heating temperature of the tank was $40{ }^{\circ} \mathrm{C}$. After the tank was covered with the IR-and thermal radiation-shielding textile, the IR images were further obtained every $10 \mathrm{~min}$ between $10 \mathrm{~min}$ to $60 \mathrm{~min}$, and were observed until $120 \mathrm{~min}$ after that. As shown in the same figure, the temperature of the textile was maintained at $26^{\circ} \mathrm{C}$ even after $120 \mathrm{~min}$. 


\section{S6. The temperature changes of the $\mathrm{PU}-\mathrm{SnO}_{2}$ microtube textile}
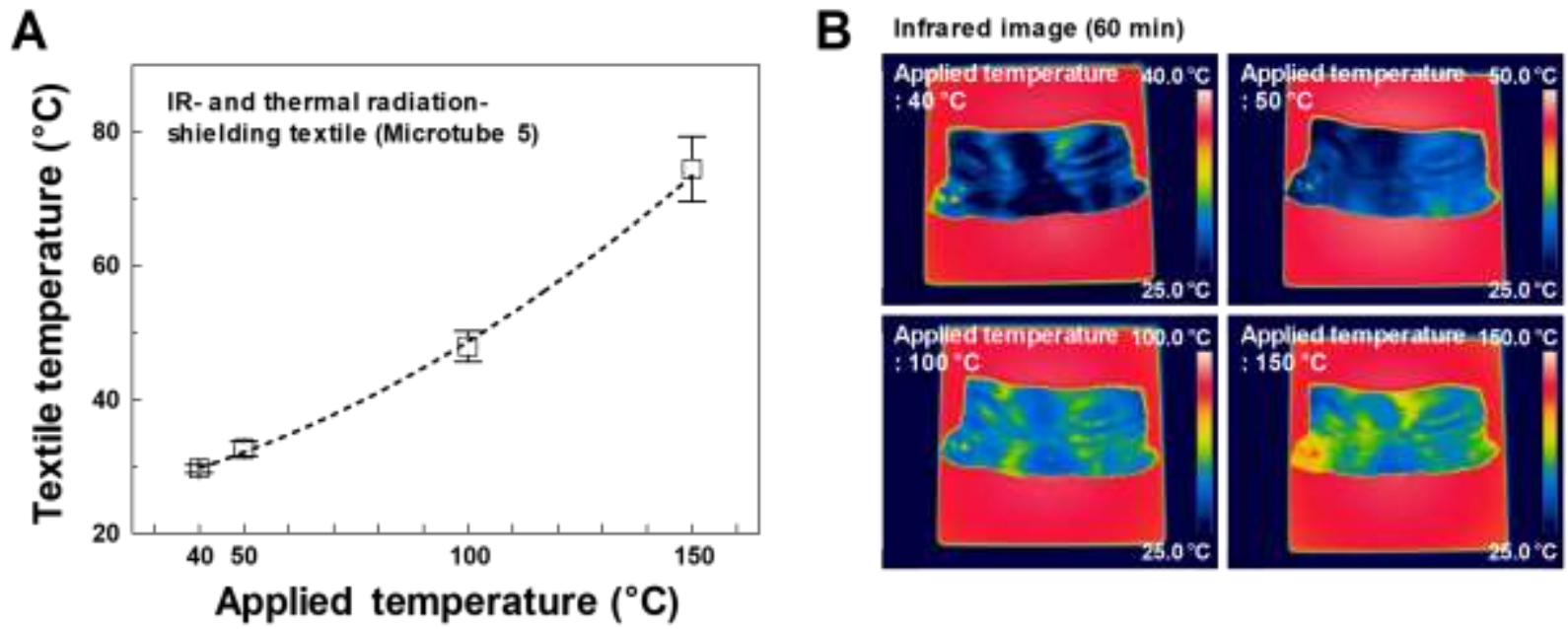

Figure S6. (A) Textile temperature and (B) IR thermal images of textiles based on $\mathrm{PU}-\mathrm{SnO}_{2}$ composite microtubes on the hot plate at $40,50,100$, and $150{ }^{\circ} \mathrm{C}$.

Figure S6 shows the temperature changes of the $\mathrm{PU}-\mathrm{SnO}_{2}$ microtube textile after increasing the hot plate temperature to $40,50,100$, and $150{ }^{\circ} \mathrm{C}$ after $60 \mathrm{~min}$ by an IR thermography camera. The $\mathrm{PU}-\mathrm{SnO}_{2}$ microtube textile was kept as close as possible to the hot plate, ensuring that the heat is propagated as well as possible. Due to the heat- and thermal IR-shielding effect of the fabricated PU-SnO 2 microtube textile, lower temperatures $(30.0 \pm 0.6,32.6 \pm 1.1,47.9 \pm 2.3$, and $74.4 \pm$ $\left.4.9{ }^{\circ} \mathrm{C}\right)$ compared with the applied temperatures $\left(40,50,100\right.$, and $150{ }^{\circ} \mathrm{C}$, respectively) were observed. 
S7. Wettability of three types of textiles produced using $\mathrm{PU}_{-} \mathrm{SnO}_{2}$ composite microtubes filled with air, paraffin oil, or water
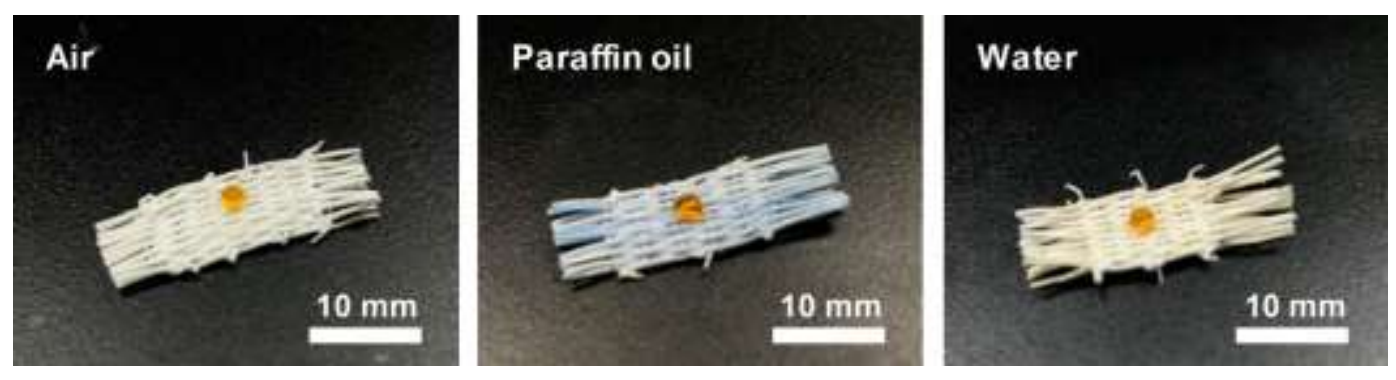

Figure S7. Demonstration of the hydrophobicity of the $\mathrm{PU}-\mathrm{SnO}_{2}$ composite microtubes filled with air, paraffin oil, or water. Water droplets mixed with a dye maintained their shapes on all three types of textiles. 
S8. The simulation proceeded with the IR-and thermal radiation-shielding textiles filled with air, paraffin oil, and water
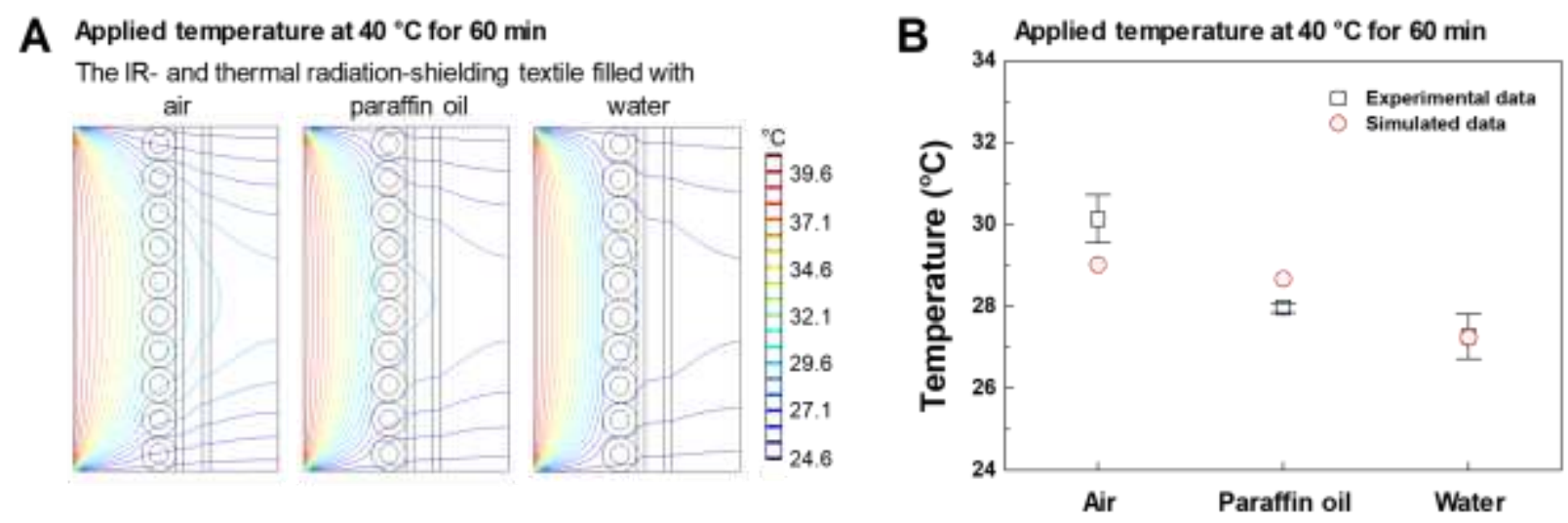

Figure S8. (A) Simulation model the IR- and thermal radiation-shielding textile filled with air, paraffin oil, and water. (B) Temperatures of the opposite side of the heat source $\left(40{ }^{\circ} \mathrm{C}, 60 \mathrm{~min}\right)$ of the IR- and thermal radiation-shielding textile filled with air, paraffin oil, and water.

Thermal properties of the IR- and thermal radiation-shielding textiles filled with air, paraffin oil, and water were simulated through the finite difference time-domain method. The simulation proceeded with the IR- and thermal radiation-shielding textiles filled with air, paraffin oil, and water arranged in one horizontal line and one vertical line. (Fig. S8(A)) One side of the PU-SnO 2 microtube was heated to $40{ }^{\circ} \mathrm{C}$ and the temperature on the opposite side of the $\mathrm{PU}-\mathrm{SnO}_{2}$ microtube was observed over time. The outer and inner diameters of the $\mathrm{PU}-\mathrm{SnO}_{2}$ microtube were set to 200 and $110 \mu \mathrm{m}$, respectively. The density of PU was set at $1,080 \mathrm{~kg} \cdot \mathrm{m}^{-3}\left(20{ }^{\circ} \mathrm{C}\right)$, the thermal conductivity of PU was $0.19 \mathrm{~W} \cdot \mathrm{m}^{-1} \cdot \mathrm{K}^{-1}$, and the specific heat of PU was $1,760 \mathrm{~J} \cdot \mathrm{kg}^{-1} \cdot \mathrm{K}^{-1}$. The density, thermal conductivity, and specific heat of air that filled up the hollow structure of the PU- 
$\mathrm{SnO}_{2}$ microtube were set to $1.205 \mathrm{~kg} \cdot \mathrm{m}^{-3}\left(20{ }^{\circ} \mathrm{C}\right), 0.0257 \mathrm{~W} \cdot \mathrm{m}^{-1} \cdot \mathrm{K}^{-1}$, and $1,005 \mathrm{~J} \cdot \mathrm{kg}^{-1} \cdot \mathrm{K}^{-1}$, respectively. In the case of paraffin oil, the density was $880 \mathrm{~kg} \cdot \mathrm{m}^{-3}\left(20{ }^{\circ} \mathrm{C}\right)$, the thermal conductivity was $0.127 \mathrm{~W} \cdot \mathrm{m}^{-1} \cdot \mathrm{K}^{-1}$, and the specific heat was $2,180 \mathrm{~J} \cdot \mathrm{kg}^{-1} \cdot \mathrm{K}^{-1}$. In the case of water, the density was $998 \mathrm{~kg} \cdot \mathrm{m}^{-3}\left(20{ }^{\circ} \mathrm{C}\right)$, the thermal conductivity was $0.602 \mathrm{~W} \cdot \mathrm{m}^{-1} \cdot \mathrm{K}^{-1}$, and the specific heat was $4,182 \mathrm{~J} \cdot \mathrm{kg}^{-1} \cdot \mathrm{K}^{-1}$. As shown in the simulation result (Fig. S8(B)), the temperature of the opposite side of the heat source decreased to $29.02,28.13$, and $27.24{ }^{\circ} \mathrm{C}$ due to the adiabatic effect of the IR thermal radiation-shielding textile filled with air, paraffin oil, and water, respectively, when a heat source at $40{ }^{\circ} \mathrm{C}$ was applied for $60 \mathrm{~min}$. Simulation values were similar to the experimental values of $30.1,28.0$, and $27.3{ }^{\circ} \mathrm{C}$. 
S9. IR transmission characteristics of conventional polyester and three types of textiles produced using PU-SnO 2 composite microtubes filled with air, paraffin oil, or water

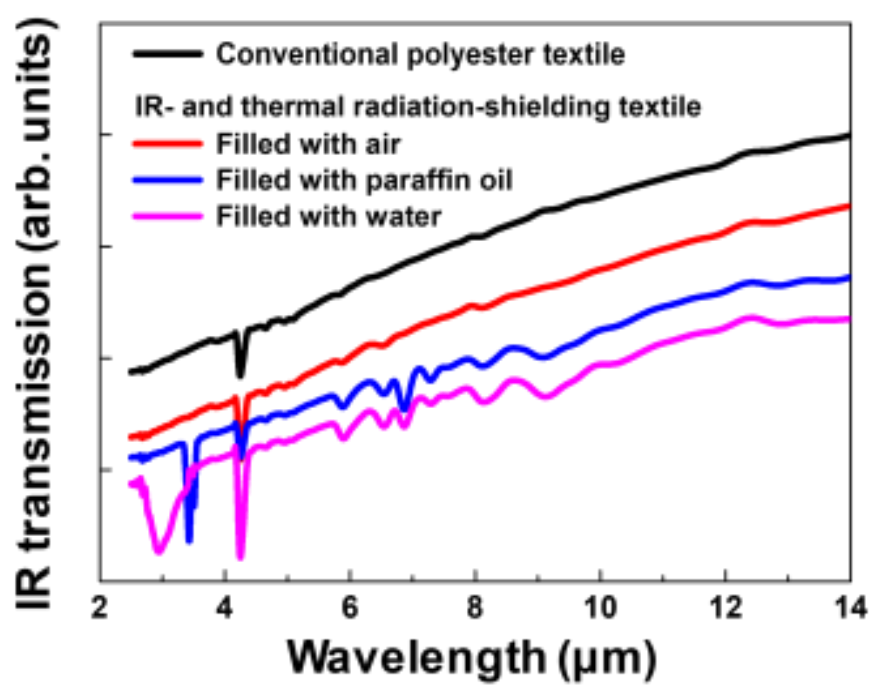

Figure S9. IR transmission characteristics of conventional polyester and $\mathrm{PU}-\mathrm{SnO}_{2}$ composite microtubes filled with air, paraffin oil, or water. The IR measurement range is $2-14 \mu \mathrm{m}$. 